\title{
The Price Mechanism Analysis of Parking Fees on Economic Perspective
}

\author{
Liqin Shan ${ }^{1} \&$ Shaodan Qian ${ }^{1}$ \\ ${ }^{1}$ School of Management, Northwest University for Nationalities, Lanzhou, China \\ Correspondence: Liqin Shan, Associate professor, School of Management, Northwest University for Nationalities, \\ Lanzhou 730030, China. E-mail: 1599864485@qq.com
}

Received: February 4, 2015

Accepted: February 12, 2015

Online Published: March 10, 2015

doi:10.5430/ijba.v6n2p118

URL: http://dx.doi.org/10.5430/ijba.v6n2p118

\begin{abstract}
Growing number of vehicles brings sever negative external effects to cities such as traffic congestion and tail gas pollution, especially to big cities. However it is the tail gas pollution which is a significant factor for the formation of haze. Gradually serious congestion and haze problems force us to face and solve the contradiction between growing demand for motor vehicles and the scarce resources of urban traffic. This paper analyzes residents' tenure and travel vehicle cost by constructing the parking price model and the linkage mechanism of parking fees-vehicle cost from the vehicle and complementary relationship of parking space in economic perspective. And this condition will affect people's desire of shopping and vehicle travel indirectly. From the consumer perspective, it will affect their choice to effectively control of motor vehicle growth, decrease usage amount, and promote the allocation of urban transportation resources. Finally, we can get a policy enlightenment that city managers can use price mechanism of parking fees to improve the efficiency of the urban traffic from several aspects, like speeding up the property rights reform bus, establishing adjustment system of dynamic price, implementing the policy of differentiation parking, optimizing the bus system and appropriately limiting parking supply.
\end{abstract}

Keywords: parking fees, economics, supply-demand model

\section{Introduction}

With the improvement of social economy and people's living standard, the number of China's vehicles is increasing sharply. However, this has caused serious negative impact: traffic congestion and exhaust pollution, with the latter as the major reason for smog. Such problems not only harm the efficiency of production and life and sustainable development, but also threaten the well-being and life safety of urban residents. The effective management of urban traffic relies on the balance between traffic supply and demand. Therefore, one solution is to step up the development of transportation infrastructure (including the upgrading of relevant technologies). The other is to strengthen the management and control of traffic demand, so as to curb the excessive growth of it.

According to the famous Coase Theorem in transportation economics, "Once the Government does not exercise effective control of urban traffic, new roads will induce a new traffic problems, so that, the traffic demand always exceeds supply", we know that it is always limited to reduce traffic demand by increasing the transportation resources. Transportation demand management has become highly regarded as the governance focusing on the total amount of the traffic increasement. Usually the city governance manages the traffic demand by using restriction method such as odd-even traffic restrictions and limitation of car number, not only the infringement of private property rights, and these measures only inhibition on the surface, and obscures the real needs, palliative, short-term effect is obvious. But soon, the real demand will purchase more vehicles released by consumers and appear new and more severe congestion. The growing demand for vehicles with limited urban transportation resource capacity to produce increasingly sharp contradiction, and traditional public governance thinking helpless or little effect in terms of solving this contradiction.

Economics is the study of the best allocation of scarce resources. From an economic perspective, the use of fully complementary relationship between the vehicle and the parking spaces and parking fees and parking fees price mechanism linkages effects between the cost of the vehicle, the impact of consumer ownership and cost of travel of the vehicle, and then the impact of car travel willness and wishes of consumers, the impact of their travel mode choice, and to achieve effective thinking this contradiction effective control of the vehicle growth and promote 
optimal allocation of urban roads, parking and other transportation resources is the solution to solve the growing problem of urban blocking and haze for the fundamental problem .

\section{Pricing Mechanism Analysis of the Parking Fee}

\subsection{The Economic Analysis of the Parking Spaces and the Vehicles}

Economic significance of perfectly complementary products always refers to a fixed percentage of consumer goods together. From an economic point of view, parking and vehicle are mutually complementary and the perfect complements. The ratio of parking and vehicle is $1: 1$, that is, for the tenure of one to be matched with a parking space in order to perform its functions.

Starting from the hypothesis of economic man, consumer vehicle and the parking utility function can be expressed as

$$
U(x 1, x 2)=\min \{x 1, x 2\}
$$

Where, $\mathrm{x} 1$ represents the number of vehicles, $\mathrm{x} 2$ is the number of parking spaces, symbols min indicate the minimum level of utility.

Consumer indifference curves are shown as shown in Figure 1. The horizontal line represents a parking space, and matching accommodates a car, any excess vehicle configuring only one parking space is unnecessary. The vertical line represents for a car needed only one parking space, any excess parking spaces be configured when a car is superfluous.

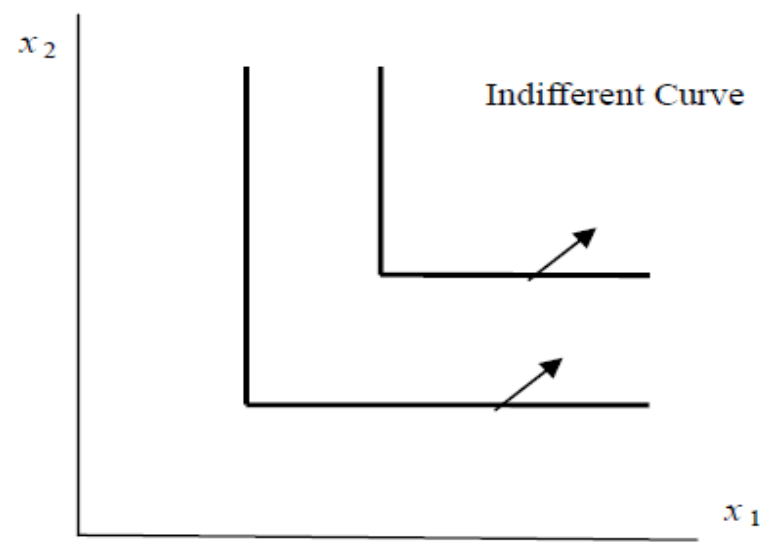

Figure 1. The indifference curve (parking space, vehicle) of fully complements

Economics is the analysis of limited resources for the realization of optimal selection problem. Consumer choice theory at finite resources of urban traffic conditions is to pursuit urban residents' welfare in which the city managers should select transportation resources and afford optimal consumption bundle. As shown in Figure 2, the best choice is the point on the diagonal no matter how the price of the vehicle and the parking space, consumer car parking spaces should be equal to the number.

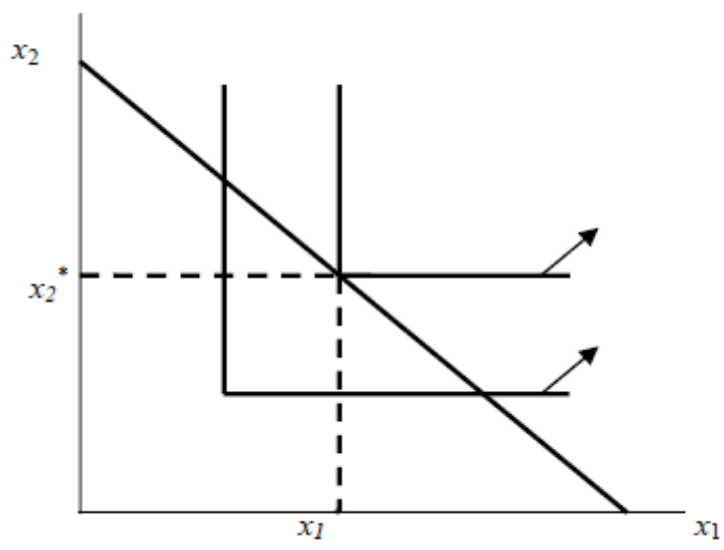

Figues 2 . The optimal choice for fully complements 
Determining the optimal choice of using algebraic methods of reasoning as follows

Vehicle price is $\mathrm{P} 1, \mathrm{P} 2$ parking charges. $\mathrm{X} 1$ is the number of vehicles, $\mathrm{X} 2$ indicates the number of parking spaces. Urban traffic resources $\mathrm{m}$ of its budget constraint as follows:

$$
p 1 \times 1+p 2 \times 2=m
$$

Solving $\mathrm{x}$, we have the number of vehicles and the number of parking spaces in the best choice

$$
x_{1}{ }^{*}=x_{2}{ }^{*}=x=m /\left(p_{1}+p_{2}\right)
$$

From the above conclusions we should get that best objectives of urban governance of the vehicle: urban growth should be subject to the limit on the number of vehicles parking spaces, the best growth should maintain the same speed and parking. Consumer choice model described above can be used for analysis of consumer willingness to purchase the best choice. Consumers' vehicle (ownership, travel) and fully complements parking utility function is:

$$
U\left(x_{1}, x_{2}\right)=\min \left\{x_{1}, x_{2}\right\}
$$

Where the number of vehicles is $\mathrm{x} 1$, number of parking spaces for $\mathrm{x} 2$, consumer spending for car is $\mathrm{m}$, the budget constraint equation is $\mathrm{p} 1 \mathrm{x} 1+\mathrm{p} 2 \times 2=\mathrm{m}$, where the vehicle price is $\mathrm{p} 1$, parking fees is $\mathrm{p} 2$.

As consumers the best choice for buying a car can be drawn

$$
x_{1}{ }^{*}=x_{2}{ }^{*}=x=m /\left(p_{1}+p_{2}\right)
$$

That is whether consumers will consider not only the vehicle purchase price, will be considered after the car in parking fees. P2 higher parking fees, $\mathrm{m} /(\mathrm{p} 1+\mathrm{p} 2)$, the smaller the value, the smaller the number of vehicles $\mathrm{x} 1$ *.

\subsection{Parking Pricing Mechanism Analysis}

Based on the above analysis, we can make parking pricing leverage to achieve more rational allocation of limited transportation resources.

First we have the parking supply and demand model as the Figure 3. The basic assumptions are as follows: all parking spaces provided by the Government, because the value of land and land restrictions, the parking spaces provided by the Government is ultimately limited. Parking space supply curve for the Government during a certain period in a variety of possible pay is willing and able to provide the number of parking spaces for rent. It initially rises with increasing of parking fees. Because land is influenced by urban ultimately limited and fixed number shown as a vertical line; vehicle owners to the parking to the demand side are the demand curve D1, D2, D3. With the growth of vehicle, the owner increased demand for parking spaces, characterized by moving up the demand curve to the right. Parking fees are demand-side price of renting parking space. Because vehicles have externalities can bring traffic congestion, pollution and other negative externalities, external costs, therefore, city managers through parking vehicles of external costs into account in order to achieve the aim of regulating vehicles and traffic balancing resources. E1, E2, E3, E4 is the market demand and supply of parking spaces between the two opposing forces balance. P1, P2, P3 are different demand curves formed by the forces of supply and demand balance in case the equilibrium price and Q1, Q2, Q3, is proportional to the number of parking spaces.

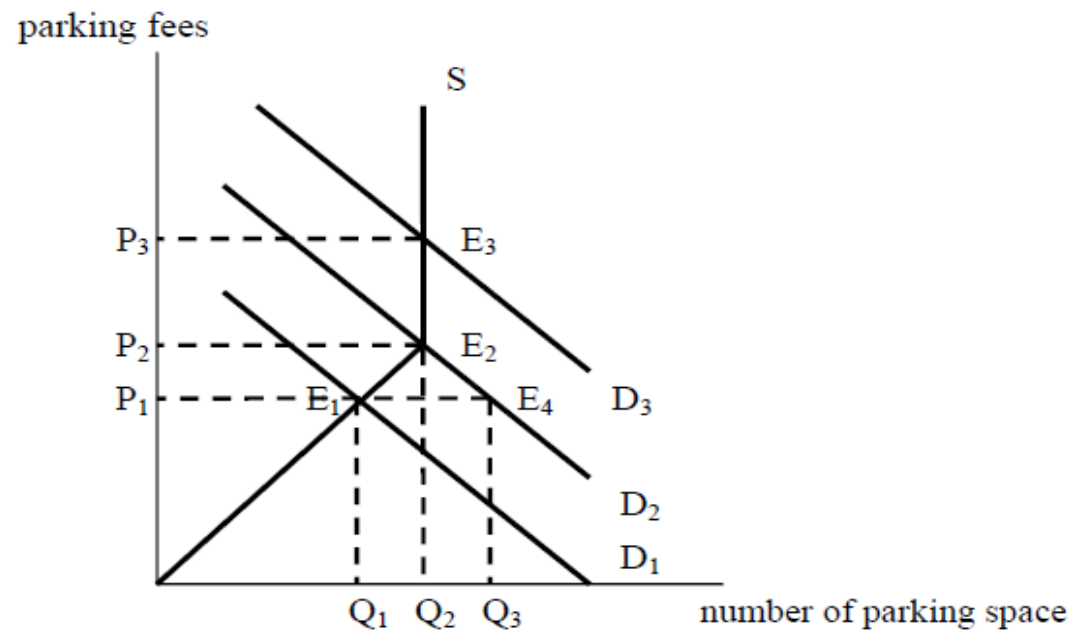

Figure 3. Supply and demand model of parking 
Using the model of supply and demand we first analyze the traffic jams, which are how the excessive vehicles occur in the case of traffic demand over the supplies of vehicles. Parking supply and demand curve initial balanced at points E1, when vehicles increase, the complementary relationship cause parking needs to increase in the first round, the demand curve right moves right to D2, the new equilibrium point will be in E2, the price of parking fees is $\mathrm{P} 2$ reflecting the increase in vehicle brought about by external costs (congestion, exhaust pollution, etc.), the actual parking demand and supply are equal, the equilibrium quantity is Q2. However, if the parking fee increases Q3 level lags behind the vehicle speed increases, remains at P1 level, it did not reflect the increase in external costs caused by vehicles, the actual parking demand intersect at equilibrium E4, and because the lower parking fees will increase to because the parking spaces and vehicles are completely complementary relationship, then the actual vehicle demand growth to Q3 levels. The numbers between Q2 to Q3 is excess demand for urban transportation resources, urban transport will be a serious shortage of resources.

Therefore, how to solve the excessive growth of vehicle and traffic congestion problems? Parking fees apply price leverage to adjust parking fee increases speed, external costs caused by an increase in the vehicle included parking fees, parking fees through timely price increases to reduce resident car or vehicle travel demand, in terms of price and limited leverage to make parking supply and demand balance, the optimal allocation of limited resources, urban transport, it will significantly reduce traffic congestion, exhaust pollution. In Figure 3, the fixed supply curve S and the initial demand curve intersects D1 E1 point. In equilibrium point E1, parking fees is P1, the equilibrium quantity is Q1. Residents of the vehicle growth has led to increased demand for parking spaces, so parking demand curve to the right level to move the position of the curve D2, D2 curve and S-curve intersect at the point E2. In equilibrium point E2, parking fees rise to $\mathrm{P} 2, \mathrm{Q} 2$ is the maximum number of urban equilibrium parking supply. With the continued growth in demand for vehicle parking flat curve to the right to move to D3, D3 curve and S-curve intersect at E3 points. In equilibrium E3, parking fees rise to P3. With the growth in vehicle parking fees increases, the external costs of vehicles are recognized, the actual demand for parking restrictions effectively, through the fixed ratio (1:1)of parking spaces and vehicle configuration costs linkage effects will effectively limit the growth in vehicle population, to achieve the most optimal allocation of resources in urban traffic.

The model shows that to achieve optimal allocation of resources in urban traffic parking fees, rental of parking spaces that price to reflect the growth in demand for parking spaces, to reflect the increase in external costs caused by vehicles. To increase the speed of synchronization with the rising parking demand, but also because completely complementary relationship with vehicle parking, increasing in parking fee should keep pace proportional to the speed of the vehicle growth rate.

\subsection{Vehicle Parking Charges Cost-Effect Analysis}

Parking price mechanism to play the role of market allocation of resources to achieve a relatively balanced urban transportation resources and the number of vehicles, including a parking fee - played vehicle cost linkage effects. In the parking fees - the cost of vehicles linkage effects, the level of parking fees by fully complementary relationship between the direct impact on consumer vehicles (ownership, travel) of the static and dynamic costs, thus their willingness to purchase, whether travel, travel mode and other consumer vehicles choose an important impact, specifically in the following:

\subsubsection{The Impacts of Parking Fees on Private Travel Consumptions}

Because those who travel by car parking fee is the cost of a part directly affects the price of car travel demand. Increase parking fees will lead to the desire to reduce private car travel, prompting more people to choose public transport.

\subsubsection{Parking Fees on Consumer Choice and Travel Time Have Important Implications Parking Duration}

Parking fee price differentiation can inhibit the relevant area, parking demand within the relevant time, reduce traffic-related areas.

\subsubsection{Parking Fees on Consumer Impact of Route Options}

If travelers expect higher parking fees, they will change their route, or you can choose lower-cost parking in parking, then change to the other means of transport to reach their destinations. If some large cities, due to central area parking stress, coupled with higher parking fees, travelers tend to park your car at the edge of the city, public transport interchange station (subway), own and ride public transport into the city centre. From this aspect, the parking is to adjust the structure of urban traffic plays a certain role, relieve traffic congestion.

\subsubsection{The Effects of Parking Fees for Consumers to Buy Vehicles}

Parking places and vehicles are perfect complements, the parking fee is an important factor to consider for 
consumers to buy vehicles. Stop setting prices, negative external effects of vehicles, namely traffic congestion and exhaust pollution in the external cost into consideration, through higher parking fees lower car buyers will influence consumer choices and achieve optimal social configuration of the number of vehicles and traffic resources.

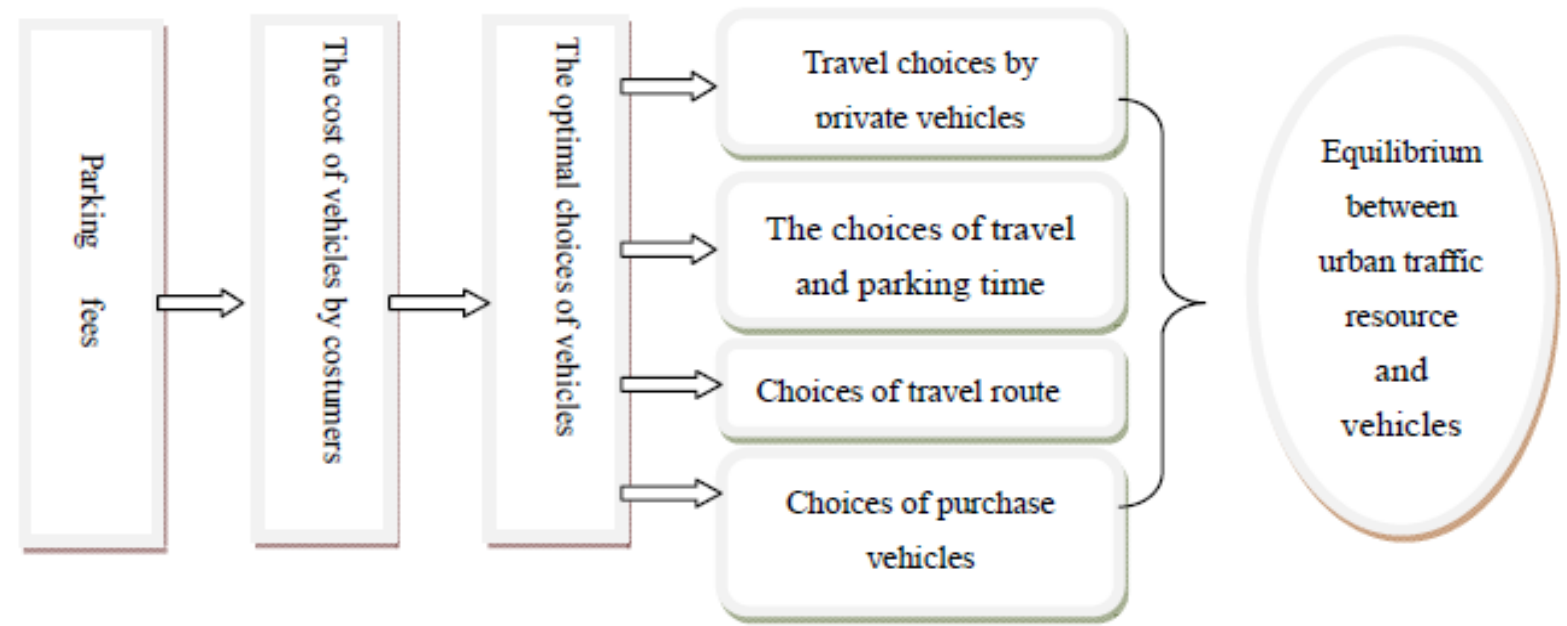

Figure 4. Vehicle cost- the linkage effect of parking

\section{Conclusions and Policy Implications}

From the perspective of economic use of pricing mechanisms can be implemented on vehicles parking fees effective control of excessive growth, is one of the most direct means to manage traffic demand, but play a role into practice also need to implement a series of scientific and rational policy on parking fees and other complementary measures. Specifically the following several points:

\subsection{Speeding up Property Rights Reform of the Bus}

According to the data issued by The Ministry of Finance, Development and Reform Commission of the People's Republic of China, the total numbers of official vehicles in the government departments and institutions and other relevant departments was more than two million, purchase of official vehicles increase every year with $20 \%$. Compared with cars, bus property right deficiency and birth defects, and aimed at the efficient consumer choice theory does not apply to bus purchases and travel. Under our current system characteristics of bus management of soft budget constraint, pursuing his own most effective bus users tend not to consider parking fees when you factor in travel, parking fees leverage to influence consumer buying decisions, and the bus trip decision. Therefore, the Government should promote the reform of property rights of bus and achieve clear ownership and large bus groups included in the category of market economy operating efficiency in governance, the parking lever in the larger context of the promotion of the optimal allocation of resources.

\subsection{Establishing the Dynamic Parking Price Adjustment System}

The regional dynamic adjustment mechanism of parking price should be formed. Increasing in parking fee should maintain the same growth rate proportional to the motor vehicle. The use of the price mechanism are parking fees prior management nature, that is, before the problem occurred on controls to prevent more serious traffic congestion, haze, difficult parking and other conditions arise oriented. The growth of motor vehicles subject to personal disposable income, prices, price alternatives and preferences and other factors change, so the dynamics of price adjustment system, parking fees should be made to adjust the standard deviation warning system and according to many influencing factors, according to the market in advance orientation, to establish a scientific parking fees formation mechanism.

\subsection{Implementing Differentiated Parking Fees Policy}

At present, the standard of most parking fees and traffic resource scarcity appears upside down, for example, parking for convenient on-street parking, above-ground parking fees, underground parking, parking charge is higher. Bad parking policy to mislead the flow direction of the vehicle, leading to increased traffic congestion, inefficient use of scarce resources, but also had a negative impact on the enthusiasm of developers to build parking lots. Scientific and reasonable parking fees policies should be based on vehicle type, region, time period, and the difference in the growth of motor vehicles has made different adjustments. 


\subsubsection{Charging on Different Types of Vehicles}

The number of different models of car parking spaces occupied by the degree of occupancy costs and exhaust pollution vary. Parking standards should be developed according to the proportion of fixed-size car parking fees, when exceptions occur, or reduce parking fees may be charged different amounts on the basis of this standard, and how much money should the city decide according to their own economic situation

\subsubsection{Charging on Different Locations and Places}

In the cities, the downtown area is located in the city center due to gather a lot of business, entertainment, finance, and other places a tremendous amount of traffic, which is more likely to cause traffic congestion, parking tension and exhaust pollution and other issues. Thus, in the development of the parking fee policy, the city should be divided into different parking area, the most expensive downtown parking fees, in order to reduce fees outward from the central region.

\subsubsection{Charging on Different Period of Time}

The daytime parking demand is rigid demand caused by the work, and is the focus of regulation of traffic, parking demand at night caused the vehicle to maintain a static traffic demand. Two different demands determine the mechanism parking standards should be different. In order to achieve the maximum benefit of parking spaces, parking fees should daytime hourly rate, calculated using a progressive system. The night parking flexible approach should be a monthly subscription or pay per view.

\subsection{Optimizing Transportation System}

A rise in parking fees by controlling the number and usage of the vehicle, while the city manager should also develop and optimize its alternatives: urban transit systems. Status quo for the development of urban public transport itself, can take a variety of car incentives: Increase bus lanes, increasing bus station (buses) and some bus routes for free and so on. Improve the public transport system can change the way people travel, try to guide the public to take in the central city bus travel, reduce the amount of travel of the vehicle in the center of the city, improve transportation access speed, promote the optimization of the structure of traffic travel, ease traffic congestion and parking difficulties situation. Ride transportation development, promote traffic volume grew to a large volume of transportation transfer, guide the way residents travel in order to reach a new equilibrium transportation resources.

\subsection{Appropriate Restrictions on the Supply of Parking Spaces}

According to a complementary relationship between the parking, the vehicles, the restrictions vehicles from parking supply can limit the demand. Therefore, the city manager on policy arrangements by limiting the supply of parking spaces, especially the supply of parking spaces in the heart of the city, to maintain a high level of parking a vehicle to increase consumer costs, reduce car use to guide their frequency and flow, reduce vehicle use external costs caused to achieve optimal allocation of transportation resources.

\section{References}

Fan, Wenbo. (2013). Oxford City Park and Ride Experience and Implications. Transportation Engineering and Information Technology, 11(1), 40-46.

Fan, Yifang, \& Yang, Liya. (2013). Parking Optimal Allocation of Resources. Beijing: Capital University of Economics and Business, 3, 100-104.

Fang, Zhang, Yi, Shan, \& Wang, Zhan. (2013). Medium-sized City's Central Business District Parking Analysis. Jilin University (Engineering Science), 43(5), 1236-1240.

Jia, Fan. (2012). The Impact of Urban Planning and Traffic Parking Study. Lanzhou: Lanzhou Jiaotong University, 20-25.

R. Hal Varian. (2013). Microeconomics Modern View. Shanghai: Polytechnic Press, pp.50-120.

Tang, Pengcheng. (2011). City Parking Fees and Congestion Charges Price Linkage Study. Heilongjiang: Harbin Institute of Technology, 85-88.

Vikan Weiqi Ke. (2012). Urban Public Transport Operations, Planning and Economic - Planning and Economic Part (The Book). Song end, He Shiwei, translated Beijing: China Railway Publishing House, pp.219-230.

Yue, Fangfei, \& Shen, Ying. (2010). Congestion Charging Feasibility Spring Explore Beijing. Beijing: Beijing Social Sciences, 1, 33-37. 